\title{
Environmental predictors of bovine Eimeria infection in western Kenya
}

\author{
D. N. Makau ${ }^{1}$ - G. K. Gitau ${ }^{2}$ - G. K. Muchemi ${ }^{1}$ - L. F. Thomas ${ }^{3,4}$ • E. A. J. Cook ${ }^{3,4}$. \\ N. A. Wardrop ${ }^{5}$ E. M. Fèvre ${ }^{3,6}$ - W. A. de Glanville ${ }^{3,4}$
}

Received: 27 September 2016 / Accepted: 5 December 2016/Published online: 4 January 2017

(C) The Author(s) 2017. This article is published with open access at Springerlink.com

\begin{abstract}
Eimeriosis is caused by a protozoan infection affecting most domestic animal species. Outbreaks in cattle are associated with various environmental factors in temperate climates but limited work has been done in tropical settings. The objective of this work was to determine the prevalence and environmental factors associated with bovine Eimeria spp. infection in a mixed farming area of western Kenya. A total of 983 cattle were sampled from 226 cattle-keeping households. Faecal samples were collected directly from the rectum via digital extraction and analysed for the presence of Eimeria spp. infection using the MacMaster technique. Individual and household level predictors of infection were explored using mixed effects logistic regression. The prevalence of individual animal Eimeria infection was $32.8 \%$ (95\% CI 29.9-35.9). A positive linear relationship was
\end{abstract}

D. N. Makau

dennmak003@gmail.com

$\triangle$ W. A. de Glanville

Will.deGlanville@glasgow.ac.uk

1 Department of Public Health Pharmacology and Toxicology, Faculty of Veterinary Medicine, University of Nairobi, Nairobi PO BOX 29053-00625, Kenya

2 Department of Clinical Studies, Faculty of Veterinary Medicine, University of Nairobi, Nairobi PO BOX 29053-00625, Kenya

3 International Livestock Research Institute, Old Naivasha Road, PO Box 30709-00100, Nairobi, Kenya

4 Centre for Immunity, Infection and Evolution, Institute for Immunology and Infection Research, School of Biological Sciences, Kings Buildings, University of Edinburgh, West Mains Road, Edinburgh EH9 3JT, UK

5 Geography and Environment, University of Southampton, Highfield Campus, University Road, Southampton SO17 1BJ, UK

6 Institute of Infection and Global Health, University of Liverpool, Leahurst Campus, Neston CH64 7TE, UK found between risk of Eimeria infection and increasing temperature $(\mathrm{OR}=1.4,95 \% \mathrm{CI} 1.06-1.86)$ and distance to areas at risk of flooding $(\mathrm{OR}=1.49,95 \%$ CI 1.17-1.91). There was weak evidence of non-linear relationship between Eimeria infection and the proportion of the area around a household that was classified as swamp (OR $=1.12,95 \%$ CI $0.87-1.44$; OR (quadratic term) $=0.85,95 \%$ CI $0.73-1.00$ ), and the sand content of the soil $(\mathrm{OR}=1.18,95 \%$ CI $0.91-1.53 ;$ OR (quadratic term $)=1.1,95 \%$ CI 0.99-1.23). The risk of animal Eimeria spp. infection is influenced by a number of climatic and soil-associated conditions.

Keywords Eimeria · Bovine $\cdot$ Tropical $\cdot$ Environmental · Extensive production systems

\section{Introduction}

Eimeriosis affects a wide range of animal species and is caused by infection with protozoa in the Eimeria genus, previously known as Coccidia. Eimeriosis in cattle is characterised by diarrhoea, fever, anorexia, weight loss, emaciation and sometimes death, particularly in young animals (Coetzer and Justin 2004). Transmission occurs following ingestion of sporoblasts in the environment. These undergo the first and second stages of schizogony in the small and large intestines, respectively, before gametogony in the colon. Oocysts are then passed in faeces to the environment where sporogony takes place and infection of another host can occur after ingestion of these oocysts with sporoblasts (Urquhart et al. 1996). Outbreaks of the disease have previously been found to be associated with environmental stressors, including low temperatures during cold seasons (Rodríguez et al. 1996; Maas 2007). A number of studies have also looked at management-related factors influencing Eimeria spp. infection in cattle. These include housing system, feeding system, watering system, floor type and herd size (Khan et al. 
2013). Environmental conditions in cattle sheds, which influence the survival and sporulation of infective oocysts, have also been shown to influence risk of infection (Lassen et al. 2009).

While management factors and very cold weather conditions have been shown to be associated with increased clinical disease in herds in temperate settings, there has been relatively little research on the effect of environmental factors on the epidemiology of eimeriosis in the tropics. In a study done in Zimbabwe to assess the effects of season on gastrointestinal parasitism in cattle, Pfukenyi et al. (2007) reported that high rainfall was significantly associated with high OPG counts of Eimeria parasites. In another study in South Africa, Matjila and Penzhorn (2002) reported that the prevalence of Eimeria infection was highest in dairy farms that were nearest to the Pienaars River.

Soil composition has also been observed to influence oocyst recovery rate and identification (Lélu et al. 2011), with similar effects observed for a number of other protozoal parasites such as Cryptosporidium and Toxoplasma (Lélu et al. 2011).

The aim of this study was to determine the prevalence of bovine Eimeria spp. infection in cattle in a small-holder farming area of western Kenya and to assess individual and herd level factors associated with infection, with a particular focus on identifying environmental predictors.

\section{Methods}

\section{Study area}

All data were collected as part of the People, Animals and their Zoonoses (PAZ) project between August 2010 and July 2012 (Doble and Fevre 2010). The study area was in Busia, Bungoma, Siaya and Kakamega counties in western Kenya (Fig. 1). This is an area with a predominantly small-scale, mixed-farming system, in which livestock production is integrated with agricultural production. The median cattle herd size is five animals of predominantly short-horn zebu breed, with animals typically managed using a mixture of tethered and free grazing systems on communal grazing lands (Bronsvoort et al. 2013).

\section{Ethical approval}

Ethical approval for the animal elements of the study was provided by the Animal Welfare and Ethical Review Body of the Roslin Institute, University of Edinburgh, UK (AWA004).

\section{Sample collection}

The PAZ study was focused on zoonotic pathogens in people and animals and was designed to detect the lowest expected prevalence of $5 \%$ in the bovine population with $2 \%$ standard error at the $95 \%$ confidence interval and a design effect of 3 . A multistage sampling approach was adopted, with households randomly selected within sublocations, the smallest administrative unit in Kenya. All sublocations within $45 \mathrm{~km}$ of the study field station, located in Busia town, were included. Between 1 and 8 households were selected in each sublocation, with the number selected proportional to the cattle population present in the sublocation. Household selection involved the generation of an appropriate number of random points in each sublocation using a geographic information system (ArcMap 9.1, ESRI, Redlands CA). The closest consenting household that was within $300 \mathrm{~m}$ of the actual location of the random point was then selected for inclusion. A back-up point was used when there was no household within $300 \mathrm{~m}$. Both livestock and non-livestock keeping households were included in the PAZ study. In each randomly selected household, a comprehensive household-level questionnaire was administered and data on herd profile, husbandry and management were obtained. All cattle within selected households were sampled, excluding those in the last trimester of pregnancy. Faecal samples were collected directly from the rectum via digital extraction. All faecal samples were analysed using the MacMaster technique (Levecke et al. 2012) to determine the presence or absence of Eimeria spp. oocysts. An individual was considered positive if oocysts were observed under microscopic examination.

\section{Predictors of Eimeria infection}

Environmental predictors of Eimeria spp. infection considered a priori to be important in this setting were the proportion of a $1 \mathrm{~km}$ area around a household that was classified as crops and grassland; the proportion of the same area around a household classified as swamp land; household distance from water bodies (Wardrop 2015); distance from areas at risk of flooding; average maximum green vegetation fraction (MGVF) (Broxton et al. 2014); average temperature; average precipitation (Hijmans et al. 2005); and soil sand content (Hengl et al. 2013). Environmental data were derived for the study area from a range of sources, as described by Wardrop et al. (2015). The average and range of values for these environmental variables are presented in Table 1. Sampling for PAZ was carried out continually for 2 years, and to explore rainfall mediated seasonal effects on Eimeria infection, we also derived values for the average rainfall measured in the 30 days prior to the sampling visit to a household from the nearest weather station with consistent data (Kisumu, latitude $=-0.09$, longitude $=34.73$, www. wunderground.com). Household geographic position and altitude were derived using a handheld GPS (Garmin eTrex). Household grazing system (zero or tethered grazing vs. free grazing) was extracted from the household questionnaire. Age based on dentition (dichotomised to $<18$ months and $\geq 18$ months), sex and breed (local zebu vs. pure breed exotic dairy cattle and their crosses) were included as predictors at the individual level. All continuous 

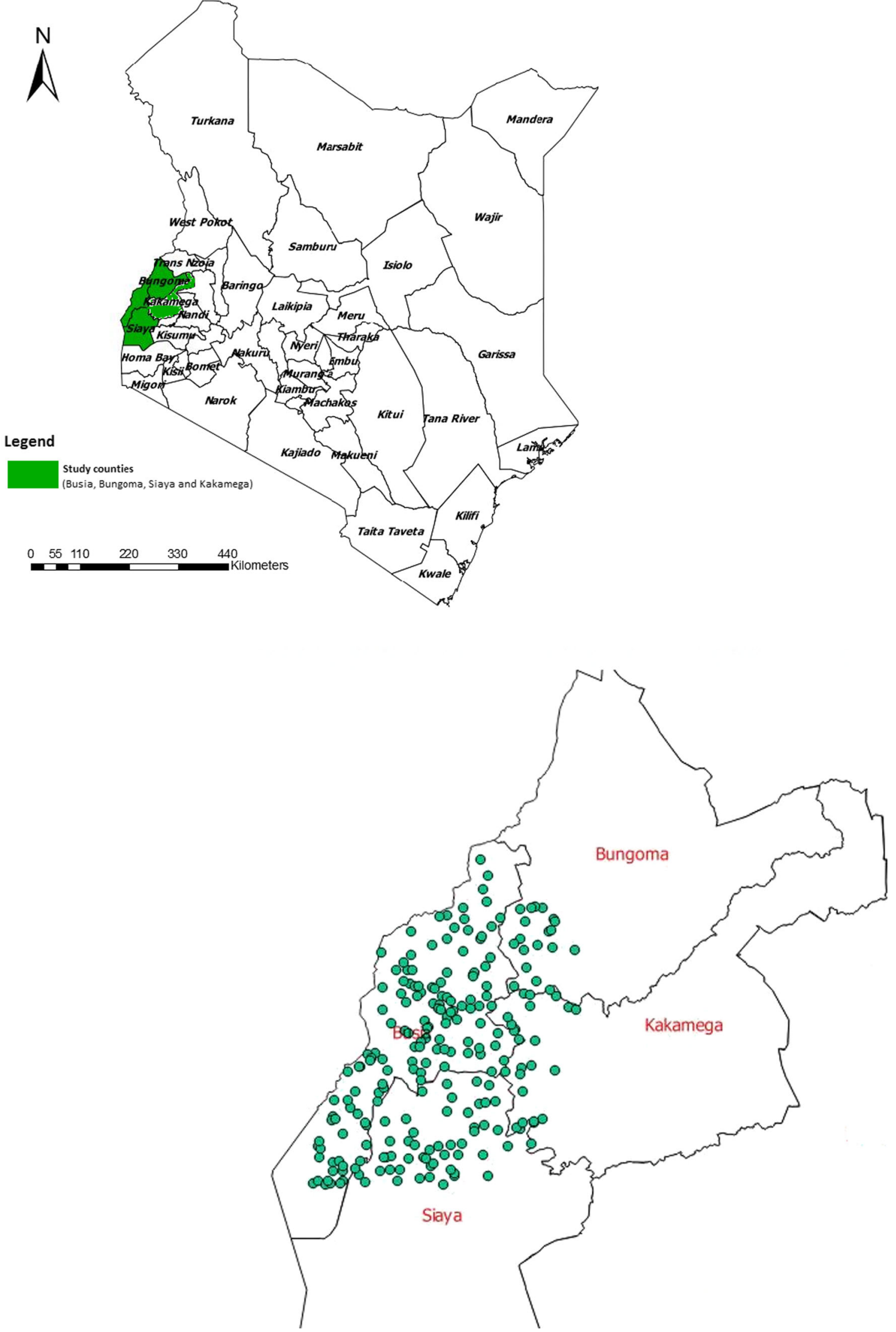

Fig. 1 Study area in western Kenya, including location of sampled households 
Table 1 Summary of environmental determinants analysed in four counties in western Kenya

\begin{tabular}{lll}
\hline Factor & Average & Range \\
\hline Percentage crop or grass land in 1 km area surrounding household & $60.68 \%$ & $35.83-78.10 \%$ \\
Percentage swamp land in 1 km area surrounding household & $7.48 \%$ & $0-36.41 \%$ \\
Soil sand content & $42.39 \%$ & $22-51 \%$ \\
pH of surface water & 5.6 & $5.2-6.3$ \\
Temperature & $22.1{ }^{\circ} \mathrm{C}$ & $21.2-22.8^{\circ} \mathrm{C}$ \\
Distance to water body & $2826 \mathrm{~m}$ & $88-9305 \mathrm{~m}$ \\
Distance to areas at risk of flooding & $985 \mathrm{~m}$ & $0-5636 \mathrm{~m}$ \\
Average MODIS-based maximum green vegetation fraction (MGVF). & $86 \%$ & $77-93 \%$ \\
Altitude & $1225 \mathrm{~m}$ & $1127-1405 \mathrm{~m}$ \\
Precipitation & $1532 \mathrm{~mm}$ & $997-1837 \mathrm{~mm}$ \\
Average rainfall in the previous 30 days & $1.3 \mathrm{~mm}$ & $0-6.0 \mathrm{~mm}$ \\
\hline
\end{tabular}

variables were examined for outliers, and the different scales of each were standardized by subtracting the mean and dividing by the standard deviation. Correlation between continuous variables was assessed using Spearman's rank test, with one of a highly correlated pair $(\geq 0.7)$ excluded based on an assessment of the biological importance of each of a correlated pair. Correlations were explored using base commands in $R$ version 2.1.1. (http://cran.r-project.org/).

\section{Covariate relationships with Eimeria infection}

Potential non-linear relationships between the log odds of Eimeria infection and each continuous covariate were explored using the method described by Hosmer et al. (2013). For this, a categorical variable with four levels was created using quartile cut-points. A logistic regression model was then fit replacing the continuous predictor with its four-level categorical derivative, and the resulting coefficients plotted versus the mid-points of the upper three quartiles (with the lowest used as reference, and given a value of 0 ). Where the relationship was obviously linear, the continuous form of the variable was used for inference. Where a logical parametric shape (e.g. quadratic) could be observed, made biological sense, and resulted in model improvement based on Akaike's information criterion (AIC), the variable was transformed. Where the relationship appeared more complicated, a restricted cubic spline (RCS) with three knots was used. If the resulting fitted shape made biological sense and resulted in lower AIC when compared to the model containing the variable in its linear form, the RCS (defined using default cut-points (Harrell 2001, 2015) was used for inference. Restricted cubic splines were fit using the $r m s$ package in $R$ (Harrell 2015).

Continuous environmental variables transformed according to this approach were included together with categorical predictors of infection (age, sex, breed, herd management) in a full logistic regression model that included household as a random effect. The model was fit using the lme4 package in
$R$ (Bates et al. 2015). Model simplification was performed using the purposeful selection procedure described by Hosmer et al. (2013). Variables were removed from the full model in a step-wise manner if they were not significant and not a confounder. The significance threshold was set at the 0.1 alpha level, and confounding was assessed on the basis of a $20 \%$ or greater change in the value of the coefficient of any of the remaining variables following removal (Bursac et al. 2008). The final model was assessed for evidence of multicollinearity using variance inflation factors.

\section{Spatial analysis}

A spatial scan statistic using a weighted normal model was implemented in SatScan version 9 (www.satscan.org) to detect spatial clustering in Eimeria infection risk in the study area. The statistic was estimated using household level residuals extracted from a null logistic regression model containing only the intercept and household level random effect. The model was weighted using the number of cattle sampled in each household (Alton et al. 2013). A normal model was used with 999 iterations (allowing estimation of $p$ values down to 0.001 ), and a cluster size up to a maximum of $50 \%$ of observations. Household level residuals from the final logistic regression model derived from the purposeful selection procedure described above were also examined for evidence of residual spatial autocorrelation using spline correlograms using the $n c f$ package (Bjornstad 2016).

\section{Results}

\section{Summary statistics}

A total 416 households were recruited into the PAZ study. Of these, 226 had cattle and 983 individual animals were included. From these, $93 \%$ of animals had faecal samples collected. 
The study population was $66 \%$ female while Zebu breeds and short horn zebu crosses made up $77.4 \%$. A total of 295 (30.0\%) of the animals sampled were less than 18 months.

The prevalence of individual animal Eimeria infection was $32.8 \%$ (95\% CI 29.9-35.9\%). The median oocysts per gram (OPG) was 200 while the average OPG was 1447.

\section{Model selection}

High levels of correlation were observed between altitude and temperature $(r=0.97)$. Since the effect of altitude on Eimeria risk could be expected to be mediated through temperatureassociated effects on oocyst sporulation, temperature was retained in the model.

The inclusion of a quadratic term improved the fit (based on AIC, data not shown) of the proportion of the area around a household that was classified as swamp and the sandy content of soil. All other environmental predictors were included in their linear form.

The results of the final multivariable logistic regression model selected using purposeful selection are presented in Table 2. Several environmental variables were found to be associated with the risk of Eimeria infection. There was a strong positive effect of both temperature and distance to flooded areas on risk of infection. There was also some evidence of a curvilinear relationship between the risk of Eimeria infection and the proportion of the $1 \mathrm{~km}$ area around a household that was classified as swamp land as well as with the sand content of the soil. The average marginal predicted probabilities of infection based on a range of values of each of these continuous variables are presented in Fig. 2. There was strong evidence of a large effect of age on risk of Eimeria infection, with animals older than 18 months being at substantially reduced risk. There was weaker evidence that male animals were at greater risk of Eimeria infection. The distance to a water body had a large confounding effect on the coefficient

Table 2 Outputs from the multivariable logistic regression model

\begin{tabular}{lllc}
\hline Predictor & Odds ratio & $\begin{array}{l}\text { 95\% confidence } \\
\text { interval }\end{array}$ & $p$ value \\
\hline Age (>18 months) & 0.3 & $0.21-0.43$ & $<0.001$ \\
Male sex & 1.35 & $0.96-1.90$ & 0.088 \\
Soil sand content & 1.18 & $0.91-1.53$ & 0.2 \\
Soil sand content $^{2}$ & 1.1 & $0.99-1.23$ & 0.07 \\
Swampy land composition $^{2}$ & 1.12 & $0.87-1.44$ & 0.38 \\
Swampy land composition $^{2}$ & 0.85 & $0.73-1.00$ & 0.05 \\
Distance to water bodies & 0.85 & $0.68-1.06$ & 0.14 \\
Distance to flooded areas & 1.49 & $1.17-1.91$ & 0.001 \\
Temperature & 1.4 & $1.06-1.86$ & 0.02 \\
\hline
\end{tabular}

for temperature and was therefore retained in the model. Variance inflation factors were all below four.

\section{Spatial clustering}

There was no evidence of clustering of high or low values of household level residuals based on a weighted normal spatial scan statistic. The $95 \%$ confidence interval for the spline correlogram included zero up to distances of $10000 \mathrm{~m}$, indicating no evidence of residual spatial correlation in household level residuals (Fig. 3).

\section{Discussion}

This study explores the prevalence of bovine infection by Eimeria species and associated risk factors in western Kenya, in a tropical region broadly representative of smallholder livestock production systems in the Lake Victoria basin. The overall prevalence observed was $32.7 \%$ (95\% CI 29.7-35.7) while the prevalence in calves ( $<18$ months) was $48.2 \%$ (95\% CI 41.8-54.6). The observed prevalence was lower than what has been documented in other studies in similarly extensive and semi-intensive production systems. Munyua and Ngotho (1990) estimated the prevalence of bovine Eimeria infection in Kenya at 67.4\%. Pandit (2009) recorded a prevalence of $75.8 \%$ in calves in extensive and semiintensive production systems in Kashmir valley in India while Asfaw et al. (2016) reported a prevalence of $71.7 \%$ in calves kept in semi-intensive systems in Ethiopia.

In this study, age was the only individual animal level factor for which there was strong evidence for an effect on Eimeria prevalence, with animals older than 18 months being less likely to be infected. This finding has been widely observed (Lassen et al. 2009; Bangoura et al. 2012; Dong et al. 2012; Rehman et al. 2012), and it is likely that an age-related immune effect occurs for this parasite (Fiege et al. 1992). Protective immunity is generally dose dependent and is usually against infection with a homologous species (Rose 1971).

Outdoor husbandry management practices have been documented to reduce the risk of Eimeria infection in cattle (McAllister 2007; Rehman et al. 2011). This is expected to be related to differences in the survival of the oocyst in outdoor and indoor environments, as well as the effects of animal density and levels of environmental contamination, which are likely to be highest in closed housing systems (Asfaw et al. 2016; Khan et al. 2013). Animal stress, which tends to be higher in housed animals, may also be important influence on shedding (Priti et al. 2008). In our study, there was no evidence of an association between infection and husbandry practices. However, we observed that very few animals were routinely housed during the day or night: only $0.6 \%$ of the 

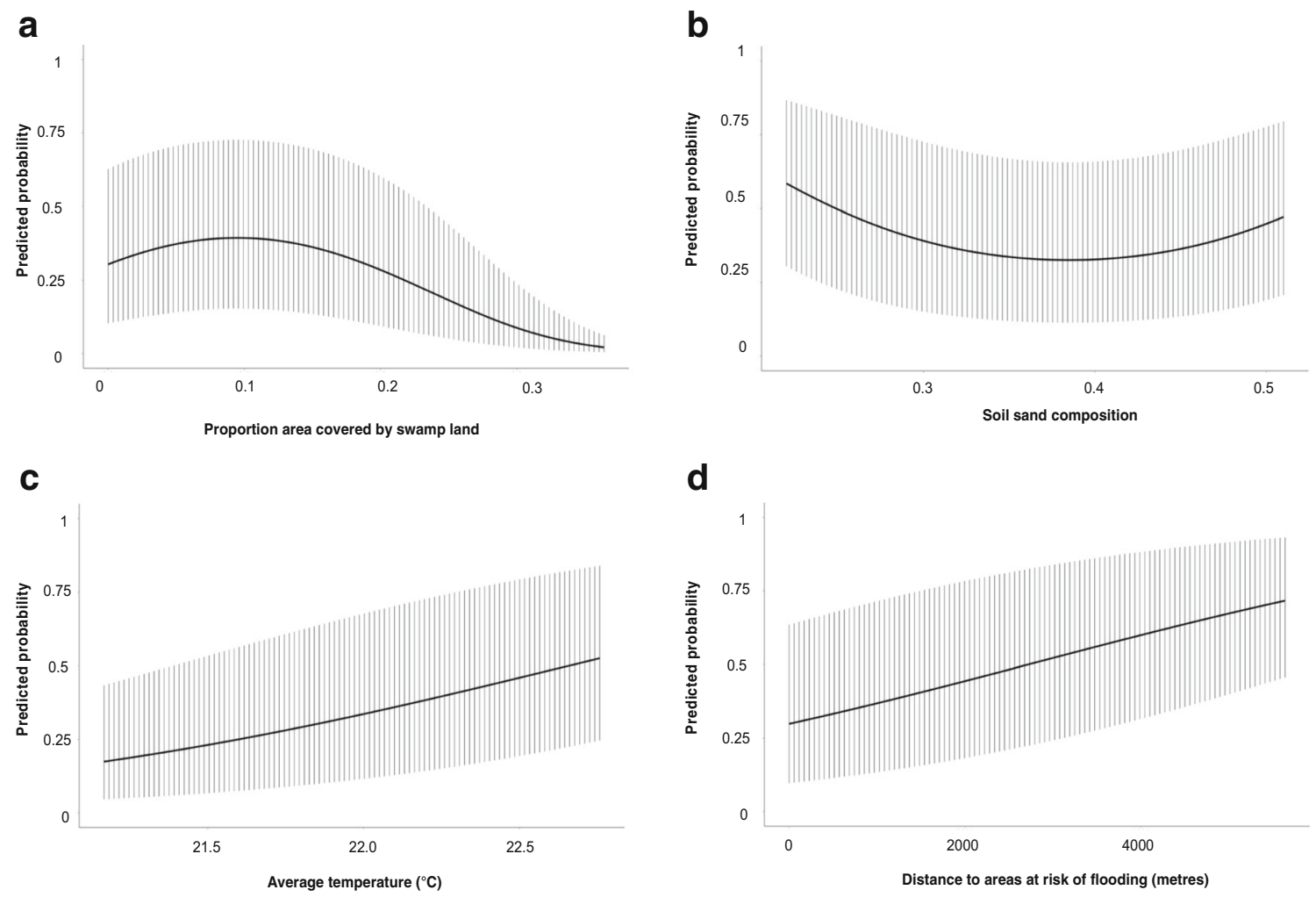

Fig. 2 Predicted average marginal probability of infection with Eimeria at a range of standardized values of the identified environmental risk factors

study population were reported to be managed under zero grazing systems throughout the whole year.

Various environmental factors were identified as being associated with Eimeria infection in cattle in the study area. In particular, there was a significant positive correlation between infection risk and increasing temperature. Warm environments are known to be favourable for the propagation of Eimeria parasites, with schizogony and sporogony occurring in warm, humid environments with adequate oxygen (Coetzer and Justin 2004). It is noteworthy that we were able to demonstrate an effect of very small temperature differences on risk of infection, suggesting these small temperature changes affect either the rate of development of oocysts and/or the duration of survival in the environment, which also impact on infection rates in animals.

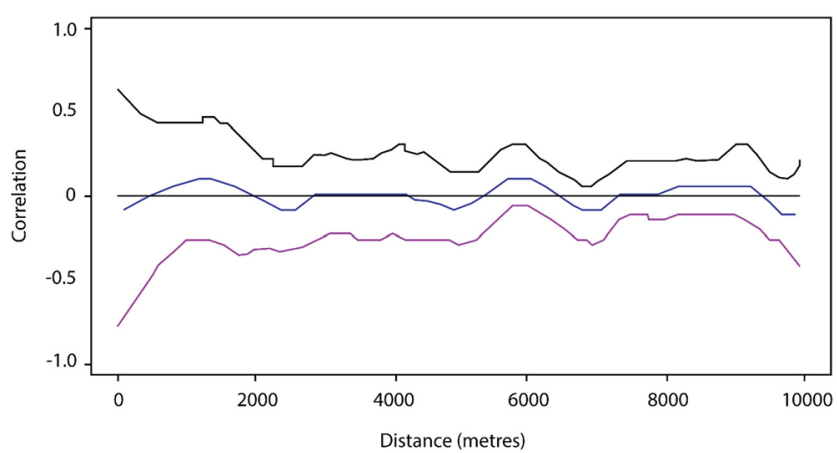

Fig. 3 Spline correlogram comparing values in household level residuals over a range of distances
Lower risk of infection was observed in individual cattle living in households that were closer to areas at risk of flooding. Such an effect could be attributed to the fact that flooded soils may be poorly aerated, with lower oxygen concentrations in the soil discouraging survival of oocysts or affecting the rate of development. For the successful completion of schizogony and sporogony, adequate oxygen concentration in the soil is needed (Coetzer and Justin 2004). Additionally, communal grazing areas that are prone to flooding may be avoided by farmers, reducing the stocking density and potential contamination of such environments for animals that live close to them.

Paradoxically, there was weak evidence of a positive association between Eimeria infection and the proportion of land surrounding a household that was covered by swamp, however, this relationship was not linear. The probability of infection increased up to almost $40 \%$ when $10 \%$ of the area around a household was classified as swamp, before decreasing to almost zero when more than $30 \%$ of the area was classified as swamp. This suggests that a small amount of swamp land creates a favourable microclimate for oocyst development, possibly through effects on humidity, but oocsyt survival or development, and animal risk, decreases once a threshold of soil moisture is reached.

Whilst we didn't observe an effect of rainfall in the previous 30 days in this study, the peak prevalence of Eimeria infections in cattle in an earlier study in Pakistan was observed in the rainy and post rainy seasons (Rehman et al. 2012). Increased 
infection risk during rainy season could be expected to occur through contamination of pasture by the parasites spreading from other areas by surface water or through humidity associated effects on oocyst survival and development (Marquardt et al. 1960). The lack of evidence of an effect observed in this study may have been due to the fact that the nearest weather station with reliable data was Kisumu, which is more than $100 \mathrm{~km}$ from the study region and closer to Lake Victoria., which tends to have higher levels of rainfall than areas further from the lake (Kenya meteorological service 2015).

There was some weak evidence of a trend towards increased risk of Eimeria infection with increasing levels of sandy soil around a household. The relationship was curvilinear, with risk of infection appearing to initially decrease as sand content increases followed by an increase in risk at relatively higher sand contents. Sandy soils have macro-pores which allow water to percolate and are rarely waterlogged (Royal Horticultural Society 2016). Their moisture levels are usually low compared to other soil types, especially clay soils (Bruand et al. 2005). Whilst the evidence is very weak ( $p=>0.05$ ), the shape of the relationship observed may provide further support to that described above for a possible threshold effect of soil moisture on oocyst development and survival. Such an effect warrants further exploration, particularly since land management practices, such as the implementation of drainage, can influence soil moisture content (Skaggs et al. 2006) and may impact on the risk of Eimeria infection.

Although eimeriosis can be a severe disease in cattle, subclinical infection is a common finding, including in temperate settings (Cornelissen et al. 1995; Farkas et al. 2007). Importantly, subclinical Eimeria infection has been associated with economic losses associated with low productivity and fertility in animals (Dedrickson 2000; Kristjanson et al. 2004; Maas 2007; Lassen 2009). A potential limitation of this study is that individual Eimeria species identification was not done, and different species could have different pathogenicity.

The prevalence of Eimeria infection in cattle in western Kenya is lower than has been recorded in other parts of the country and the world in similar production systems. While most infections are likely to be subclinical, farmers in western Kenya could consider laboratory diagnosis and treatment of positive cases to reduce production losses associated with infection. The prevalence of Eimeria in cattle in western Kenya is influenced by animal age and the temperature. The soil water content in the areas around households also appears to be important. Knowledge of these animal and environmental predictors could assist with the targeting of testing, or observation for clinical disease, to particular animals living in particular environmental conditions.

Acknowledgements We are grateful to all the members of our field and laboratory teams in Busia and Nairobi, in particular James Akoko, Omoto Lazarus, Jenipher Ambaka, Fredrick Opinya, Lorren Alumasa, Daniel
Cheruiyot, Alice Kiyong'a, Velma Kivali, George Omondi, Gideon Mwali, John Mwaniki, Hannah Kariuki, Lilian Achola and Maseno Cleophas.

Author contributions EMF, LFT conceived and designed the study. EMF, LFT, EAJC, WAdeG performed the study. NW provided data used in the study. DM, WAdeG analysed the data. DM, GG, WAdeG wrote the paper. All authors made contributions to conception, design and revision of the manuscript. All authors read and approved the final manuscript.

Compliance with ethical standards Ethical approval for the animal elements of the study was provided by the Animal Welfare and Ethical Review Body of the Roslin Institute, University of Edinburgh, UK (AWA004).

Funding The project described was supported by the Wellcome Trust (085308). LFT and WAdeG were supported by BBSRC DTG awards and EAJC by an MRC DTG award. NAW was funded by the Medical Research Council, UK (project MR/J012343/1). This work received support from the CGIAR Research Program on Agriculture for Nutrition and Health (A4NH), led by the International Food Policy Research Institute (IFPRI). The funders had no role in study design, analysis, manuscript preparation or decision to publish. We also acknowledge the CGIAR fund donors (http://www.cgiar.org/who-we-are/cgiar-fund/fund-donors-2).

Conflict of interest There was no conflict of interest cited by any of the authors or supporting parties in the research and writing of this manuscript.

Open Access This article is distributed under the terms of the Creative Commons Attribution 4.0 International License (http:// creativecommons.org/licenses/by/4.0/), which permits unrestricted use, distribution, and reproduction in any medium, provided you give appropriate credit to the original author(s) and the source, provide a link to the Creative Commons license, and indicate if changes were made.

\section{References}

Alton G.D., Pearl D. L., Bateman K.G., McNab B. and Berke O., 2013. Comparison of covariate adjustment methods using space-time scan statistics for food animal syndromic surveillance. BMC Veterinary Research, 9:231

Asfaw D., Deneke Y. and Ibrahim N., 2016. Prevalence and associated risk factors of calf coccidiosis in and around Asela Town, Southeast Ethiopia. Journal of Natural Sciences Research 6(3).

Ary Bruand, Christian Hartmann, G. Lesturgez. 2005. Physical properties of tropical sandy soils: A large range of behaviours. Management of tropical sandy soils for sustainable agriculture. confrence proceedings: a holistic approach for sustainable development of problem soils in the tropics. Khon Kaen, Thailand. 2005, 27.11.2005 au 2.12.2005.

Bangoura B., Mundt H., Schmäschke R., Westphal B., Daugschies A., 2012. Prevalence of Eimeria bovis and Eimeria zuernii in German cattle herds and factors influencing oocyst excretion. Parasitology Research 110 (2) 875.

Bates D., Maechler M., Bolker B., Walker S., 2015. Fitting linear mixedeffects models using lme4. Journal of Statistical Software, 67(1), 1-48.

Bjornstad O.N., 2016. R functions for analyzing spatial (cross-) covariance: the nonparametric (cross-) covariance, the spline correlogram, the nonparametric phase coherence function, and related. http://ento. psu.edu/directory/onb1. Accessed 15 August 2016.

Bronsvoort B. M., Thumbi S. M., Poole E. J., Kiara H., Auguet O. T., Handel I. G., Jennings A, Conradie I., Mbole-Kariuki M. N., Toye 
P.G., Hanotte O., Coetzer J.A.W., Woolhouse M.E.J., 2013. Design and descriptive epidemiology of the infectious diseases of East African Livestock (IDEAL) project, a longitudinal calf cohort study in western Kenya. BMC Veterinary Research, 9:171.

Broxton, P., X. Zeng, W. Scheftic, and P. Troch, 2014: A MODIS-Based Global 1-km Maximum green vegetation fraction dataset. Journal of Applied Meteorology and Climatology, 53.

Bursac Z., Gauss C. H., Williams D. K. and Hosmer D. W., 2008. Purposeful selection of variables in logistic regression. Source Code for Biology and Medicine 2008, 3:17

Coetzer J. A. W and Justin R. C, 2004. Infectious diseases of livestock. Second edition Vol 3; Oxford University press 319 - 331.

Cornelissen A.W., Verstegen R H., van den Brand, Perie N.M., Eysker M., Lam T.J., Pijpers A, 1995. An observational study of Eimeria species in housed cattle on Dutch dairy farms. Veterinary Parasitology 56(1-3): 7-16.

Dedrickson B. J., 2000. Coccidiosis in beef calves. Alpharma Animal Health Division Fort Lee, NJ 07024.

Doble, L., Fevre E., 2010 Focusing on neglected zoonoses, Veterinary Record, 166(18): 546-546.

Dong H., Zhao Q., Han H., Jiang L., Zhu S., Li T., Kong C., and Huang B., 2012.Prevalence of coccidial infection in dairy cattle in Shanghai, China. Shanghai Veterinary Research Institute, Chinese Academy of Agricultural Science, Key Laboratory of Animal Parasitology of Ministry of Agriculture.

Farkas R., Szeidemann Z., Majoros G., 2007. Studies on coccidiosis of calves in Hungarian dairy farms. Parasitology Research 101(1) 113120

Fiege N., Klatte D., Kollmann D. Zahner H., Bürger H. J., 1992. Eimeria bovis in cattle: colostral transfer of antibodies and immune response to experimental infections. Parasitology Research. 78 (1) 32-38.

Harrell, F., 2001. Regression modeling strategies, with applications to linear models, survival analysis and logistic regression, Springer International Publisher, Switzerland.ch2

Harrell F., 2015. Regression modeling strategies: with applications to linear models, logistic and ordinal regression, and survival analysis, Second Edition, Springer International Publisher, Switzerland.ch4

Hengl T, Heuvelink GBM, Kempen B., 2013. Soil property maps of Africa at $1 \mathrm{~km}$. https://www.isric.org: ISRIC: World Soil Information. Accessed 10 May 2016.

Hijmans RJ, Cameron SE, Parra JL, Jones PG, Jarvis A., 2005. Very high resolution interpolated climate surfaces for global land areas. International Journal of Climatology. 25:1965-78.

Hosmer, Jr., D. W., Lemeshow, S. and Sturdivant, R. X. (2013) Modelbuilding strategies and methods for logistic regression, in applied logistic regression, Third Edition, John Wiley \& Sons, Inc., Hoboken, NJ, USA.

Kenya meteorological service,2015. Weather and crop review for dekad 26, 11-20 September, $2015 \mathrm{http}: / / \mathrm{www}$.meteo.go. ke/dekad/Dekad26-2015.pdf. Accessed 15 September 2016.

Khan, M. N.; Tauseef-ur-Rehman; Sajid, M. S.; Abbas, R. Z.; Zaman, M. A..A. S. M. R. 2013. Determinants influencing prevalence of coccidiosis in Pakistani buffaloes. Journal Pakistan Veterinary Journal., 33(3), 287-290.

Kristjanson P., Krishna A., Radney M., Nondo W., 2004. Pathways out of poverty in western Kenya and role of livestock. Working paper14-. http://www.fao.org/ag/pplpi.html. Accessed 13 May 2013.

Lassen B., 2009. Diagnosis, epidemiology and control of Bovine coccidiosis in Estonia. Veterinary medicine and zootechnics 48 (70).

Lassen B, Viltropa Arvo, Raaperib K, Järvisa T, 2009. Eimeria and Cryptosporidium in Estonian dairy farms in regard to age, species, and diarrhea. Veterinary Parasitology 166, (3-4), 212-219.
Lélu, M., Gilot-Fromont, E., Aubert, D., Richaume, A., Afonso, E., Dupuis, E., Gotteland, C., Marnef, F., Poulle, M.-L., Dumètre, A., Thulliez, P., Dardé, M.- L., Villena, I. 2011. Development of sensitive method for Toxoplasma gondii oocyst extraction in soil. Veterinary Parasitology, 183, 59-67.

Levecke B, Rinaldi L, Charlier J, Maurelli MP, Bosco A, Vercruysse J, Cringoli G, 2012. The bias, accuracy and precision of fecal egg count reduction test results in cattle using McMaster, CornellWisconsin and FLOTAC egg counting methods. Veterinary Parasitology 13; 188 (1-2):194-9.

Maas J., 2007. Coccidiosis in Cattle. UCD Vet Views. Carlifornia Cattlemen's Magazine.

McAllister M., 2007. Bovine neosporosis and coccidiosis. Biológico, São Paulo, 69(2):57-61.

Marquardt, W. C., Senger, C. M. And Seghetti, L. 1960, The effect of physical and chemical agents on the oocyst of Eimeria zurnii (Protozoa, Coccidia). The Journal of Protozoology, 7: 186-189.

Matjila P., and Penzhorn B., 2002. Occurrence and diversity of bovine coccidia at three localities in South Africa. Veterinary Parasitology 104 (2): 93-102.

Munyua W.K., Ngotho J.W., 1990. Prevalence of Eimeria species in cattle in Kenya. Veterinary Parasitology 35 (1-2):163-168.

Pandit, B., 2009. Prevalence of coccidiosis in cattle in Kashmir valley. VetScan 4: (1) 33.

Pfukenyi D., Mukaratirwa S., Willingham A., and Monrad J., 2007. Epidemiological studies of parasitic gastrointestinal nematodes, cestodes and coccidia infections in cattle in the highveld and lowveld communal grazing areas of Zimbabwe Onderstepoort. Journal of Veterinary Research, 74:129-142.

Priti M, Sinha SRP, Sucheta S, Verma SB, Sharma SK, Mandal KG, 2008. Prevalence of bovine coccidiosis at Patna. Journal of Veterinary Parasitology 22:5-12.

Rehman TU., Khan MN., Sajid MS., Abbas RZ., Arshad M., Iqbal Z., Iqbal A., 2011. Epidemiology of Eimeria and associated risk factors in cattle of County Toba Tek Singh, Pakistan. Parasitology Research 108(5):1171-1177.

Rehman, T., Khan, M. N., Sajid, M. S., Iqbal, Z., Javid, M. T., Riaz, M., \& Ahmad, M. 2012. Epidemiology of Eimeria and associated risk factors in goats of district Toba Tek Singh, Pakistan. Indian Journal of Animal Sciences, 82(3), 282-285.

Rodríguez R I. -Vivas, Domínguez J L. -Alpizar, Torres J F. -Acosta, 1996. Epidemiological factors associated to bovine coccidiosis in calves (Bos indicus) in a subhumid tropical climate. Revista Biomédica 7:211-218.

Rose E M., 1971. Immunity to coccidiosis: protective effect of transferred serum in Eimeria maxima infections. Parasitology 62 (1)11-25.

Skaggs, R. Wayne; Amatya, Devendra M.; Chescheir, G. M.; Blanton, C. D.; Gilliam, J. W., 2006. Effect of drainage and management practices on hydrology of pine plantation. http://www.treesearch.fs.fed. us/pubs/22416. Accessed 15 September 2016.

The Royal Horticultural Society 2016. Soil types. https://www.rhs.org.uk. Accessed 15 September 2016.

Urquhart G.M, Armour J, Duncun J L, Dunn AM, Jennings FW, 1996. Veterinary parasitology Second edition; Blackwell Science Ltd. 224-231.

Wardrop, N A 2015. Landcover classification: western Kenya, 2010. http://eprints.soton.ac.uk/383135/ Accessed 15 May 2016.

Wardrop N. A,., Thomas L. F., Atkinson P. M., Glanville W. A., Cook E. A. J., Wamae C. N., Gabriël S., Dorny P., Harrison L. J. S., Fèvre E. M., 2015. The influence of socio-economic, behavioural and environmental factors on Taenia spp. Transmission in western Kenya: evidence from a cross-sectional survey in Humans and Pigs. PLoS Neglected Tropical Diseases 9 (12). 